\title{
TELHADO VERDE MODULAR EXTENSIVO: BIODIVERSIDADE E ADAPTAÇÃO DAS PLANTAS AOS BLOCOS TEVA
}

\section{EXTENSIVE MODULAR GREEN ROOF: BIODIVERSITY AND ADAPTATION OF PLANTS TO TEVA BLOCKS}

\author{
Tatyane Nadja Martins de Mendonça ${ }^{1}$ \\ Rede Pitágoras de Ensino, João Pessoa, Paraíba, Brasil, tatyanemartinn@gmail.com \\ Aluísio Braz de Melo 2 \\ Universidade Federal da Paraíba, João Pessoa, Paraíba, Brasil, aluisiobmelo@hotmail.com
}

\section{Resumo}

Os benefícios do uso da cobertura das edificações como telhado verde já são bem conhecidos, tanto na escala do edifício quanto na escala da cidade. Para o telhado verde extensivo modular, é interessante considerar as características quanto à flexibilidade e à praticidade, na execução e manutenção. Também é notável quando se utilizam materiais que são coerentes com a proposta de sustentabilidade ambiental. Nessa perspectiva, pode-se destacar o uso de concretos leves com resíduos da indústria de calçados para produzir os módulos a receberem vegetação. Considerando-se esse tipo de telhado verde (extensivo) e tais materiais utilizados nos módulos (pré-moldados cimentícios com resíduos de EVA), apresenta-se, neste artigo um estudo que procura identificar a biodiversidade favorecida e as interações entre os módulos e os vegetais neles cultivados. O referido telhado foi executado na cobertura de uma edificação existente no laboratório e monitorado durante nove meses, na condição de clima tropical quente e úmido. Os resultados demonstraram que várias das plantas do tipo medicinais (porte herbáceo) cultivadas se adaptaram bem ao material e ao projeto do módulo, sobretudo em relação aos espaços das células nos módulos, demandando apenas uma manutenção mensal e irrigação de 3 a 4 vezes/semana, no período com baixa precipitação pluviométrica. No micro-habitat, foram encontrados vários tipos de animais (minhocas, baratas, embuás etc.) e espécies de plantas invasoras, confirmando a hipótese de que tal ambiente auxilia na manutenção da biodiversidade.

Palavras-chave: Telhado verde. Biodiversidade. Concreto Leve. Resíduos EVA.

\begin{abstract}
The benefits of using housetops as green roofs are already well known both in building scale as well as in city scale. It is interesting to consider the characteristics of flexibility and practicality of implementation and maintenance of large modular green roof. It is also noteworthy when used materials are consistent with environmental sustainability proposals. From this perspective, one can highlight the use of lightweight concrete made from footwear industry waste to produce the modules to receive vegetation. Considering this type of green roof (extensive) and the materials used in the modules (precast cement elements with EVA waste), this article presents a study that attempts to identify the benefited biodiversity and the interactions between the modules and the plants on it. The above mentioned green roof was built over the standard roof of an existing research laboratory building, and it was monitored for nine months, under a hot and humid tropical climate condition. Results showed that several cultivated medicinal plants (herbaceous size) adapted well to the material and module design, particularly with the spaces of the cells within the modules, which only require monthly maintenance and irrigation 3-4 times per week, in low rainfall period. Several kinds of animals (worms, cockroaches, millipedes etc.) and invasive plant species were found in the micro-habitat, confirming the hypothesis that such an environment assists in maintaining biodiversity.Keywords: Green Roof. Biodiversity. Lightweight Concrete. Waste EVA.
\end{abstract}

\section{How to cite this article:}

MENDONÇA, Tatyane Nadja Martins; MELO, Aluísio Braz de. Telhado verde modular extensivo: biodiversidade e adaptação das plantas aos Blocos TEVA.PARC Pesquisa em Arquitetura e Construção, Campinas, SP, v. 8, n. 2, p. 117-126, jun. 2017. ISSN 1980-6809. Disponível em: <https://periodicos.sbu.unicamp.br/ojs/index.php/parc/article/view/8649606>. Acesso em: 15 dez. 2017. doi:http://dx.doi.org/10.20396/parc.v8i2.8649606 


\section{Introdução}

Sabe-se que os telhados verdes podem reduzir o consumo energético nas edificações, como também contribuir em vários aspectos relacionados à sustentabilidade ambiental, tais como: reduzir as ilhas de calor urbanas (quando em grande escala), mitigar a poluição do ar (pela deposição e retenção do micro particulado suspenso no ar), diminuir os fluxos das águas pluviais nos sistemas de drenagem urbanos, minorar os ruídos e aumentar a biodiversidade, dentre outros (BERARDI; GHAFFARIANHOSEINI; GHAFFARIANHOSEINI, 2014). Dentro da classificação de telhados verdes, destaca-se aqui o de tipo extensivo, que corresponde ao sistema que utiliza plantas de pequeno porte. Essa característica demanda um processo construtivo mais simples, com baixo custo de execução, desde que a sobre carga máxima na base de sustentação seja limitada a 150 $\mathrm{kg} / \mathrm{m}^{2}$. Complementando a afirmação de Berardi, Ghaffarianhoseini e Ghaffarianhoseini (2014), de que o telhado verde extensivo tem pouca necessidade de manutenção e de irrigação, a Associação Internacional de Telhados Verdes (IGRA, 2017) sugere, para o sistema extensivo, a adoção de plantas que são resistentes ao stress hídrico, como as encontradas nas regiões áridas e semiáridas. Essas plantas são mais passíveis a sobreviverem em uma superfície construída (telhados, fachadas e vias), sem um sistema de irrigação alternativo à pluviometria local.

Os telhados verdes correspondem ao desenvolvimento de vegetais nas coberturas das edificações, transformando uma cobertura inerte, em viva. Além dessa composição orgânica (plantas e substrato), sob essa camada há outras que compõem o sistema, na seguinte sequência: camada de retenção de substrato, camada de drenagem e, por fim, a base de sustentação devidamente impermeabilizada e com barreira anti raiz.

Essa nova cobertura de composição também orgânica passa a se configurar como um novo habitat para inúmeras espécies, como artrópodes, aves, dentre outros, contribuindo para a formação de novos ecossistemas. De fato, como afirmam Braker et. al. (2014), a conectividade entre esses tipos de coberturas vegetadas possibilita o fluxo das espécies, que, por sua vez, configurará maior valor ecológico para a biodiversidade local. Brenneisen (2006), Olly et. al. (2011) e Tonietto et. al. (2011), nessa mesma abordagem que ressalta o valor ecológico para a manutenção da biodiversidade local, também concordam, com base em suas pesquisas, que há potencialidades e contribuições dos telhados verdes nesse processo.

Outras pesquisas procuram destacar os impactos dos telhados vegetados em escalas mais amplas, a ponto de constituírem uma oportunidade de novos habitats para a biodiversidade das cidades. Nesse sentido, os estudos de Coffman e Waite (2011) apresentam dados sobre a diversidade de espécies que habitam telhados verdes, dentre eles: insetos, aranhas e aves. Williams et. al. (2010), a partir de uma ampla revisão das publicações que investigam sobre a diversidade biológica encontrada nas coberturas vegetadas, concluíram que os telhados verdes podem ajudar a conservar a biodiversidade urbana. A formação desses novos ecossistemas, através das coberturas vegetadas, acaba sendo muito importante para a preservação da biodiversidade local, principalmente pela escassez dos espaços naturais dentro da cidade.

Para tanto, as espécies vegetais a serem aplicadas em telhados verdes devem ser selecionadas, considerando-se a região climática, a profundidade do substrato prevista e a sistemática de irrigação programada.

Além disso, é importante a observância de outros critérios de seleção, como a ação do vento sobre 0 telhado verde, em função da altura e da forma do edifício, e a visibilidade e acessibilidade ao telhado verde. Embora Sedum seja o gênero mais utilizado nos telhados verdes, são diversas as opções para a seleção das espécies vegetais, gerando uma infinidade de possibilidades de combinações que podem ser realizadas (OBERNDORFER et. al., 2007).

Com respeito à profundidade dos substratos, estudos confirmam que profundidades pequenas, entre 2 (dois) $\mathrm{cm}$ e 5 (cinco) $\mathrm{cm}$, deixam o solo mais sujeito a variações de temperatura, inclusive com possibilidade de dessecação (perda de umidade), embora possam ser adequadas para as comunidades simples de sedummusgo. Por outro lado, em profundidades dos substratos maiores, entre 7 (sete) $\mathrm{cm}$ e 15 (quinze) cm, pode-se utilizar uma variedade maior de vegetais, mesmo que essas profundidades sejam mais hospitaleiras a ervas daninhas indesejáveis (OBERNDORFER et. al., 2007), por proporcionar maior área de desenvolvimento para as raízes.

As plantas selvagens também podem ter um papel importante nos ecossistemas de telhados verdes, pois são geralmente nativas e devem ser base da cadeia alimentar para espécies de fitófagos e polinizadores (TONIETTO et. al., 2011). Além disso, podem colonizar espontaneamente os telhados verdes e são, portanto, propícias a se espalhar dentro da paisagem urbana, como mostra o estudo experimental de Dunnett, Nagase e Hallam (2008), em Sheffield, Reino Unido, onde foram identificadas 35 espécies colonizadoras.

As condições climáticas, especialmente com relação à precipitação pluvial e às temperaturas extremas, podem restringir o uso de determinadas espécies ou ditar a 
frequência, ou ausência de irrigação nas plantas. Espécies nativas são geralmente consideradas escolhas ideais para paisagens, por causa de suas adaptações locais ao clima (OBERNDORFER et. al., 2007).

Köhler e Poll (2010), corroborando os estudos de Oberndorfer et. al. (2007), destacam também a importância da profundidade dos substratos nas características florais dos telhados verdes e no desenvolvimento de espécies espontâneas nos telhados sem manutenção. Deste modo, vale ainda fazer $o$ destaque de que os telhados verdes são dinâmicos e, com o tempo, a vegetação fica susceptível a se alterar, a partir da composição original (KÖHLER, 2006).

Ainda em relação à importância de preservar a biodiversidade local, há pesquisas que tratam de outro tipo de cobertura biológica, especificamente os telhados marrons ("brownroofs"). Esses tipos são similares aos telhados verdes, com todas as camadas anteriormente referidas, exceto a da vegetação, uma vez que, nesse caso, busca-se deixar o substrato disponível para ser colonizado naturalmente, favorecendo o desenvolvimento espontâneo das espécies vegetais e de sua respectiva fauna, como se fosse um terreno baldio. O objetivo dos telhados marrons é o de promover um maior valor ecológico para essa cobertura. Nesse sentido, Ishimatsu e Ito (2013) afirmam que os telhados marrons são capazes de favorecer um habitat mais natural para biodiversidade urbana do que os telhados verdes extensivos, ou telhados Sedum, também chamado assim pela pouca variabilidade de espécies vegetais utilizadas, geralmente ficando mais restrita ao gênero Sedum.

Com base nos referenciais apresentados, buscou-se, nesta pesquisa, discutir alguns dados, obtidos a partir de um acompanhamento sistemático, ao longo de nove meses, de um telhado verde modular extensivo, procurando verificar o comportamento da vegetação cultivada. No processo de monitoramento, foram considerados os seguintes aspectos: adequação das espécies vegetais selecionadas; periodicidade da manutenção e da irrigação; surgimento de espécies vegetais invasoras e atração de animais. Além disso, procurou-se identificar a interação entre os módulos e os vegetais neles cultivados.

\section{Materiais e Métodos}

Este estudo buscou analisar o comportamento da vegetação inserida em pré-moldados cimentícios leves, fabricados com resíduos da indústria de calçados (Etileno Acetato de Vinila - EVA), o intitulado bloco TEVA. Os blocos vegetados foram aplicados em escala natural, em uma laje de $12 \mathrm{~m}^{2}$. Um aspecto interessante na geometria do bloco TEVA projetado é sua configuração com quatro (4) células, para receber solo e vegetação, e sua versatilidade no uso para executar o telhado verde, sendo o mesmo bloco utilizado ora para receber a vegetação, ora para servir como piso, quando colocado em posição invertida (Figura 1). Essa ideia viabiliza a composição de telhados verdes com áreas parcialmente vegetada, ou seja, com blocos contendo vegetação ao lado de outros blocos invertidos, transformando-se em áreas pavimentadas, que facilitam a visitação e manutenção das plantas.

Figura 1 - Bloco TEVA proposto e sua aplicação no telhado verde extensivo modular parcialmente vegetado ao lado de área pavimentada (com blocos TEVA em posições invertidas)
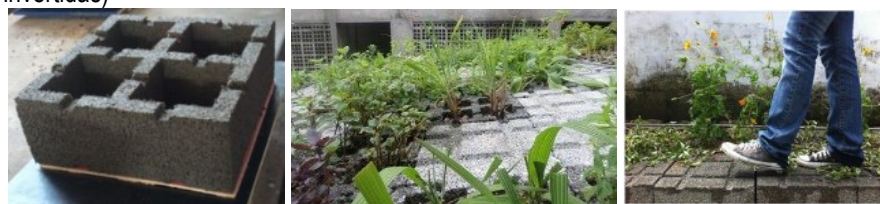

Fonte: Os autores

Outra característica importante do bloco TEVA proposto é sua adequação ao sistema de telhado verde extensivo modular. Por definição, este telhado deve ser mais leve, com sobre carga máxima na laje limitada até $150 \mathrm{~kg} / \mathrm{m}^{2}$, utilizar plantas de pequeno porte e ter o processo construtivo facilitado e manutenção simplificada, com pouca necessidade de irrigação, sendo baixo o seu custo de execução (BERARDI et. al. 2014).

Para realizar o monitoramento das plantas inseridas nos módulos, foram assentados 111 (cento e onze) blocos TEVA vegetados, numa área sobre uma laje do tipo prémoldada (com nervuras de concreto armado, blocos cerâmicos e capa de concreto), ocupando uma parte da cobertura de uma construção (somente um pavimento) existente no Laboratório de Ensaios de Materiais e Estruturas do Centro de Tecnologia da Universidade Federal da Paraíba (LABEME-CT-UFPB) (Figura 2). A construção localizava-se numa região com condição de clima tropical quente e úmido, e o seu monitoramento foi programado para ser realizado em dois períodos com diferenças importantes no volume de precipitação pluviométrica na região.

Figura 2 - Execução do telhado verde extensivo modular para realização do monitoramento

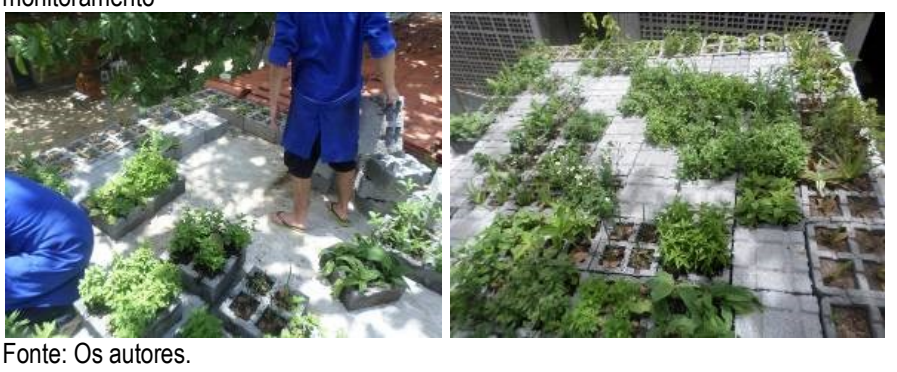

Em relação às espécies das plantas utilizadas na vegetação dos blocos, decidiu-se por utilizar apenas aquelas de usos medicinais, num total de 32 espécies 
apresentadas nos Quadros 1, 2 e 3, conforme agrupamento por famílias. Todos os blocos TEVA foram vegetados e aclimatados num intervalo de tempo de 15 dias no Centro de Biotecnologia (CBIOTEC-UFPB) e, depois disso, foram instalados no telhado verde, simulado em escala real em ambiente externo de laboratório (LABEME-CT-UFPB).

Quadro 1 - Lista das espécies vegetais da família Lamiaceae, utilizadas na pesquisa
\begin{tabular}{|c|c|c|}
\hline Nome popular & Nome científico ${ }^{1}$ & Característica \\
\hline Alecrim & Rosmarinus officinalis L. (1753) & Herbasto ramificado \\
\hline Boldo & Plectranthus barbatus Andrews (1810) & Herbácea/perene \\
\hline Erva cidreira & Melissa officinalis L. (1753) & Herbácea/perene \\
\hline Hortelã Homem & Plectranthus barbatus Andrews (1810) & Herbácea \\
\hline Hortelã da folha miúda & Mentha piperita L. (1753) & Herbácea/perene/suculenta \\
\hline Hortelã da folha graúda & Coleus amboinicus Lour (1790) & Herbácea \\
\hline Mangericão do roxo & Ocimum basilicum L. (1753) & Herbácea \\
\hline Mangericão menino & Ocimum minimum L. (1753) & Herbácea/altura $60 \mathrm{~cm}$ \\
\hline Mangerona & Origanum majorana L. (1753) & Herbácea/perene \\
\hline Poejo, Hortelãzinho, hortelã pimenta & Mentha pulegium L. (1753) & \\
\hline
\end{tabular}

1 (TROPICOS, 2017)

Fonte: Os autores.

Quadro 2 - Lista das espécies vegetais de outras 4 (quatro) famílias diferentes (Asteraceae, Zingiberaceae, Amaranthaceae e Crassulaceae), utilizadas na pesquisa

\begin{tabular}{|c|c|c|c|}
\hline Nome popular & Familia & Nome científico ${ }^{1}$ & Característica $^{\text {Herbácea/perene }}$ \\
\hline Agrião do brejo & Asteraceae & Spilanthes acmella (L.) L. (1774) & Herbácea/perene \\
\hline Camomila & Asteraceae & Matricaria recutita L. (1753) & Subarbusto/perene \\
\hline Erva lanceta & Asteraceae & Solidago chilensis Meyen (1834) & Herbácea/perene \\
\hline Malmequer amarelo & Asteraceae & Aspilia montevidensis (Spreng.) Kuntze (1898) & Herbácea/perene \\
\hline Colônia & Zingiberaceae & Alpinia zerumbet. Pers. B.L. Burtt.\& R.M.Sm & Herbácea/perene \\
\hline Gengibre & Zingiberaceae & Zingiber officinale Roscoe (1807) & Herbácea \\
\hline Mastruz & Amaranthaceae & Chenopodium ambrosioides L. (1753) & Herbácea/perene/ereta \\
\hline Penicilina & Amaranthaceae & Alternanthera brasiliana (L.) Kuntze (1891) & Suculenta \\
\hline Saião & Crassulaceae & Kalanchoe brasiliensis Cambess & Suculenta \\
\hline Saião do roxo & Crassulaceae & Kalanchoe crenata (Andrews) Haw (1812) & \\
\hline
\end{tabular}

1 (TROPICOS, 2017)

Fonte: Os autores.

Quadro 3 - Lista das espécies vegetais de outras 12 (doze) famílias diferentes, utilizadas na pesquisa

\begin{tabular}{|c|c|c|c|}
\hline Quadro 3 Lista das especies vegetais de outras 12 (doze) familias diferentes, utilizadas na pesquisa & Nome científico ${ }^{1}$ & Característica \\
\hline Agrião do Pará & Famílias & Nasturtium officinale W.T. Aiton (1812) & Herbácea/perene \\
\hline Alho do mato & Brassicaceae & Cipura paludosa Aubl. (1775) & Suculenta \\
\hline Babosa & Iridaceae & Aloe vera (L.) Burm. f. (1768) & Herbácea \\
\hline Bunina (da flor roxa) & Nynthorrhoeaceae & Mirabilis jalapa L. (1753) & Herbácea/perene \\
\hline Cavalinha & Equisetaceae & Equisetum giganteum L. (1759) & Herbácea/altura 50 cm \\
\hline Chachambá (anador) & Acanthaceae & Justicia pectoralis Jacq (1760) & Herbácea \\
\hline Capim santo & Poaceae & Cymbopogon citratus (DC.) Stapf & Herbácea de haste dura \\
\hline Cana de macaco & Costaceae & Costus spicatus (Jacq.) Sw. (1788) & Trepadeira \\
\hline Milona & Menispermaceae & Cissampelos sympodialis Eichler (1864) & Herbácea/pequena \\
\hline Quebra pedra & Phyllanthaceae & Phyllanthus niruri L. (1753) & Herbácea \\
\hline Salsa & Apiaceae & Petroselinum sativum Hoffm. (1814) & Herbácea/perene \\
\hline Tansagem & Plantaginaceae & Plantago major L. (1753) & \\
\hline
\end{tabular}

1 (TROPICOS, 2017)

Fonte: Os autores

Para simular o telhado verde extensivo modular na construção existente no laboratório (LABEME-CTUFPB), parte de sua coberta teve que ser preparada. Inicialmente, foram removidas as telhas cerâmicas que estavam assentadas diretamente sobre a laje de concreto (área correspondente a $12 \mathrm{~m}^{2}$ ), sendo, em seguida, feita a limpeza do local e a aplicação de uma impermeabilização à base de tinta acrílica. Na sequência, os blocos TEVA, já vegetados, foram dispostos sobre a laje.

A primeira etapa de monitoramento da vegetação inserida nos blocos TEVA corresponde ao período de 4 (quatro) meses de 2014 (junho/setembro), durante o qual os vegetais transplantados nos blocos não receberam nenhuma atenção especial, com relação à irrigação, 
nutrição ou poda. Destaca-se que esse período corresponde ao período chuvoso (4 meses), ou seja, aquele com maior precipitação pluviométrica $(171,9 \mathrm{~mm}$ de média mensal; com média máxima da umidade relativa do ar igual a $81,2 \%$; e com média máxima da temperatura do ar igual a $26,1^{\circ} \mathrm{C}$ (INMET, 2016) para o período do estudo) na cidade (João Pessoa-PB) onde o experimento foi realizado. $\mathrm{O}$ interesse, nessa etapa do estudo, foi acompanhar o comportamento dos vegetais, diante das condições naturais do clima (tropical quente e úmido) e do microclima locais. Cabe registrar que nas proximidades da construção onde o telhado verde foi instalado há muita arborização de grande porte, bem como outras construções (com dois pavimentos), que produzem sombreamentos sobre o telhado verde em teste, durante alguns períodos do dia (início da manhã e final da tarde). Somente no final da primeira etapa foi feita uma manutenção nos vegetais, retirando os vegetais ressecados e, quando era o caso, fazendo o replantio com novas mudas nos mesmos blocos TEVA.

A segunda etapa, como novo ciclo de acompanhamento dos vegetais, foi realizada durante os próximos 5 (cinco) meses (outubro 2014 a fevereiro 2015). Esse período compreende a estação mais seca na cidade (João PessoaPB) onde o estudo foi realizado, de baixa precipitação pluviométrica com média mensal para o período igual a $33,8 \mathrm{~mm}$. A média máxima da umidade relativa do ar foi igual a $73,7 \%$ e a média máxima da temperatura do ar foi igual a $28,7^{\circ} \mathrm{C}$ (INMET, 2016), conforme se vê na Figura 3. Durante o período mais seco, realizou-se uma manutenção mínima, caracterizada por uma aspersão com água sobre a vegetação, entre 3 a 4 vezes por semana. Também se fez, em algumas datas aleatórias (a cada dois meses), a retirada da gema apical dos vegetais, a fim de diminuir o crescimento horizontal; a retirada de folhas secas; a remoção de algumas plantas que não sobreviveram e o replantio de novas mudas com as gemas apicais retiradas das plantas desenvolvidas, além da reposição parcial de substrato.

Para a configuração do telhado verde em questão, foram adotadas as seguintes diretrizes: 1 - definição de caminhos para as eventuais visitações de pessoas; 2 alcance das pessoas a todas as áreas com vegetação, a partir dos caminhos definidos. Portanto, a ideia foi posicionar todos os blocos TEVA de modo a definir ilhas vegetadas próximas de áreas com pisos (com blocos TEVA em posições invertidas), possibilitando às pessoas caminharem com facilidade e segurança, tanto em caso de visitação como para a manutenção, permitindo o fácil acesso aos módulos vegetados, conforme se verifica na Figura 4. Evidentemente, outros arranjos eram possíveis, considerando que a leveza dos blocos TEVA permitia, mesmo após serem vegetados, fácil transferência de um local para outro, por apenas uma pessoa. As diversas possibilidades de arranjos (ilhas vegetadas $\mathrm{x}$ pisos), que podem ser executadas a cada momento, constitui outra característica interessante da aplicação dos blocos TEVA na execução de telhado verde extensivo modular.

Figura 3 - Dados para a cidade (João Pessoa-PB) onde foi simulado o telhado verde extensivo modular com blocos TEVA, com monitoramento por 9 meses 2014/2015 (períodos chuvoso e seco)

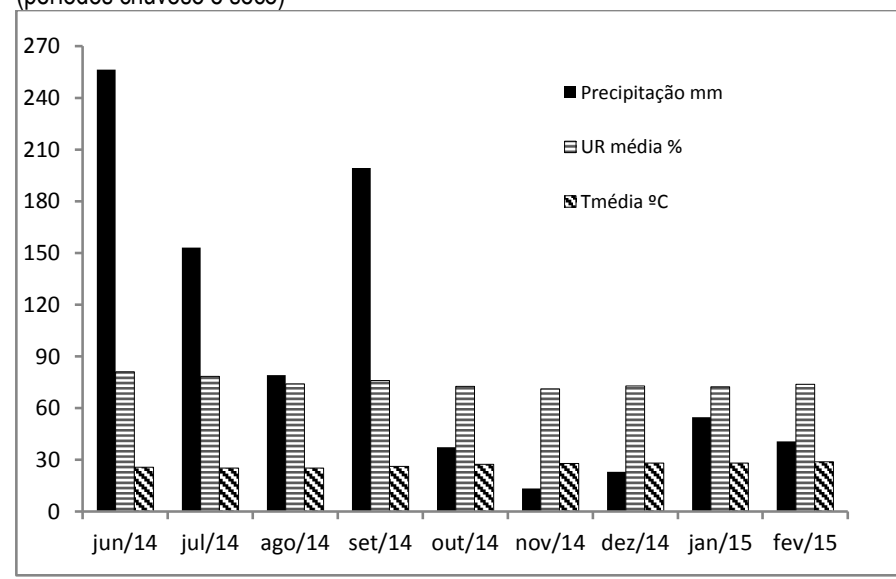

Fonte: BDMEP (INMET, 2016) para João Pessoa-PB.

Figura 4 - Arranjo dos blocos TEVA (vegetados ou em posições invertidas), configurando o telhado verde extensivo modular em teste

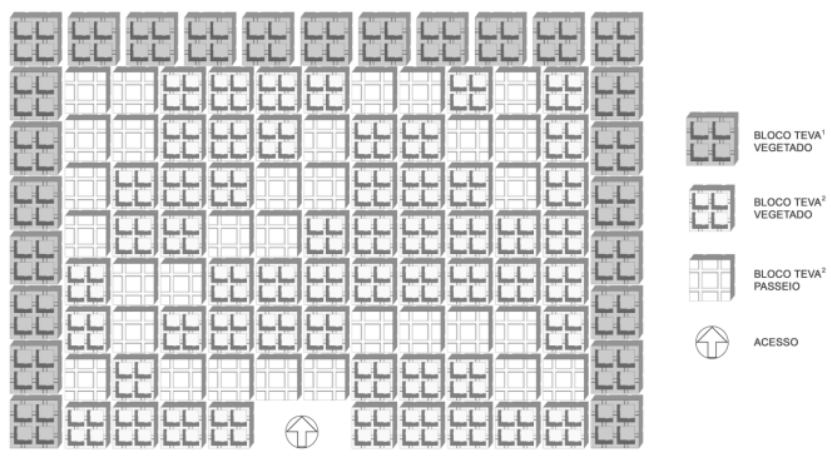

Fonte: Os autores.

Para a execução desse telhado verde, foram utilizados 25 blocos (TEVA $\left.{ }^{1}\right)$, com dimensões iguais a $35 \mathrm{~cm}$ (largura) x $35 \mathrm{~cm}$ (comprimento) x $13 \mathrm{~cm}$ (altura), e outros 86 blocos $\left(\mathrm{TEVA}^{2}\right)$, com dimensões iguais a $30 \mathrm{~cm}$ (largura) x $30 \mathrm{~cm}$ (comprimento) x $13 \mathrm{~cm}$ (altura). Considerando as pequenas diferenças dimensionais entre os blocos TEVA, optou-se por colocar os maiores (25 blocos TEVA1), delimitando a área para o telhado verde extensivo modular (bordas da coberta e divisa entre telhado verde e telhado cerâmico), conforme se mostra na Figura 4.

\section{Resultados e Discussões}

Os resultados desta pesquisa permitiram verificar o comportamento dos vegetais inseridos nas células dos blocos TEVA, aplicados no telhado verde extensivo modular, simulado em escala real em ambiente externo de laboratório (LABEME-CT-UFPB), na condição de 
clima tropical quente e úmido, e também observar a biodiversidade atraída por este tipo de cobertura. O monitoramento foi dividido em dois períodos climáticos característicos do local: um deles como primeira etapa, período chuvoso; e outro como segunda etapa, período seco.

\section{$1^{\text {a }}$ ETAPA - período chuvoso}

As observações relativas ao acompanhamento desta etapa (junho a setembro 2014) mostram que o sistema radicular ultrapassou a base do bloco TEVA1, como visto na Figura 5.

Figura 5 - Imagem da base dos blocos TEVA aparecendo o sistema radicular dos vegetais plantados nas suas células
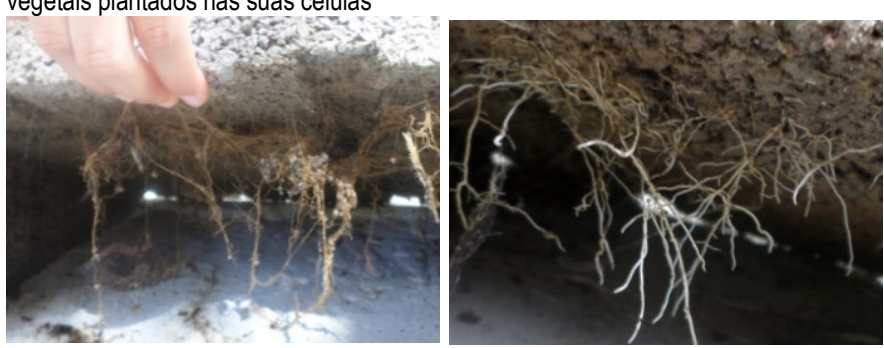

Fonte: Os autores

Essa ocorrência revela que, mesmo nesse caso, há necessidade da utilização de um tipo de manta como barreira anti raiz, entre a base dos blocos TEVA e a laje impermeabilizada ou a própria membrana impermeabilizante com barreira anti raiz. Percebe-se que isso ocorreu num curto período de observação e, embora as raízes não tenham, de fato, se fixado na laje, confirmou-se a importância da proteção, proporcionada pela manta anti raiz, como é indicação para todos os sistemas de telhados verdes.

A segunda observação é que o telhado verde com blocos TEVA, já nos 4 meses iniciais, favoreceu o desenvolvimento da biodiversidade, uma vez que, neste período de acompanhamento, foi possível encontrar, tanto animais quanto outros vegetais (considerados invasores). Desta forma, confirma-se a formação de micro-habitat no local onde os blocos TEVA vegetados estavam dispostos sobre a laje (Figura 6).

Há de se notar que, apesar de se visualizar um pouco de substrato (solo) sob o bloco TEVA, de fato, não ocorreu vazamento desse material através da sua base. $\mathrm{Na}$ verdade, quando os blocos TEVA foram vegetados, eles estavam apoiados diretamente sobre a terra (solo/material natural), sem nenhum tipo de revestimento/proteção entre o solo e os blocos. Assim, a porção inferior dos blocos TEVA ficou impregnada pelo solo local, que foi sendo desprendida depois de colocados no telhado verde em teste, formando os aglomerados de solo. Outro fato interessante foi constatar a presença de minhocas nos poros maiores na base do bloco TEVA (Figura 6).
Destaca-se que a presença desse animal no sistema é algo bem favorável, pois o mesmo atuará beneficiando a aeração do solo.

Figura 6 - Destaque da biodiversidade atraída pelo telhado verde extensivo modular com blocos TEVA ( $1^{\text {a }}$ etapa - período chuvoso)

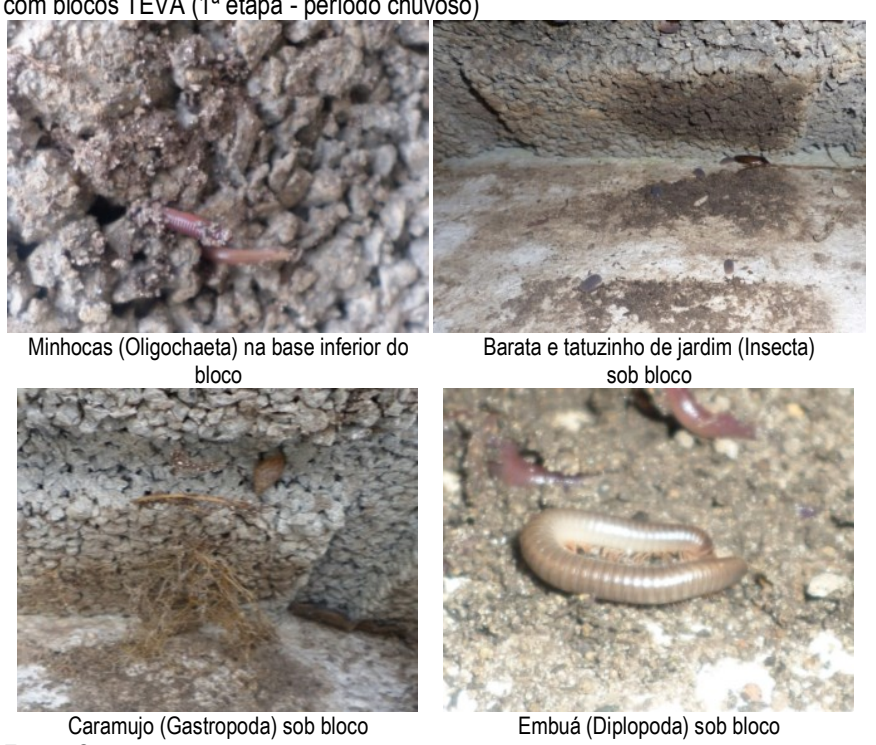

Fonte: Os autores.

Os vegetais que apresentaram um melhor desenvolvimento, nesta primeira etapa, foram os seguintes: Coleus amboinicus (hortelã da folha grossa), Kalanchoe brasiliensis (saião do verde), Kalanchoe crenata (saião do roxo); Plectranthus barbatus (boldo); Costus spicatus (cana de macaco); Aloe vera (babosa) e Alternanthera brasiliana (penicilina).

De modo geral, observou-se também perda parcial desse substrato (solo) no interior do bloco TEVA, talvez devido à ação do vento e da chuva no período, o que indicou a necessidade de sua reposição. Isso só ocorreu após três (3) meses de monitoramento (praticamente no final desse ciclo de observação), quando foi feita a única manutenção dos blocos TEVA vegetados e instalados no telhado verde em teste.

Apesar disto, nesta mesma manutenção, no momento da retirada dos vegetais que não se adaptaram às condições, notou-se também uma boa fixação das raízes ao substrato, o que é bem positivo pela possibilidade de diminuir a perda do substrato pela ação das intempéries (ação dos ventos, por exemplo). Como se trata de telhado verde que está instalado em cobertura, caso o substrato esteja seco e facilmente desprendido e/ou desprotegido $\mathrm{da} /$ pela vegetação, a incidência direta de ventos no local pode favorecer o movimento de material particulado (poeira em suspensão), a partir do substrato, carreando material para fora dos blocos.

O comportamento notável foi observado para as hortelãs da folha graúda que se desenvolveram bastante em relação às outras espécies. Então, decidiu-se retirá-las, e, 
com as suas gemas apicais, foram feitos replantios nos mesmos blocos originais e reposições com esses vegetais em outros blocos TEVA, cujas espécies não haviam resistido e/ou se adaptado às condições do micro clima natural, durante o período de observação.

\section{$2^{\mathrm{a}}$ ETAPA - período seco}

O telhado verde monitorado, na segunda etapa de acompanhamento, corresponde ao período seco (com pouca chuva). Esse período de acompanhamento (outubro 2014/fevereiro 2015), praticamente incluiu todo o período correspondente à estação de verão na cidade (João Pessoa-PB). A Figura 7 apresenta os registros com imagens, aproximadamente, a partir do mesmo ponto de observação desse telhado verde, as quais foram produzidas a cada 30 dias, quando ocorria a manutenção e o acompanhamento do desenvolvimento dos vegetais.

Figura 7 - Desenvolvimento dos vegetais no telhado verde extensivo modular, durante 5 meses ( $2^{\mathrm{a}}$ etapa - período seco)

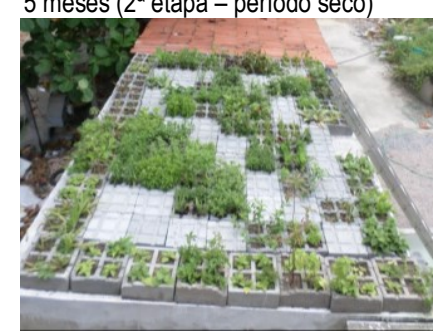

$06 / 10 / 2014$

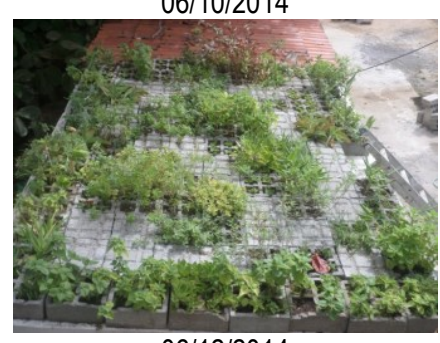

$06 / 12 / 2014$

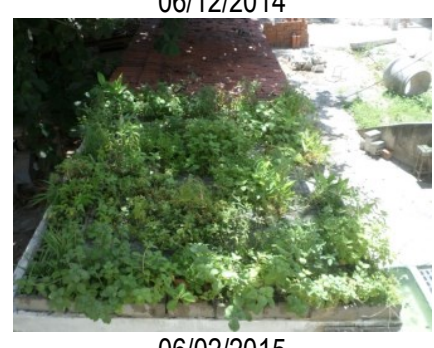

$06 / 02 / 2015$

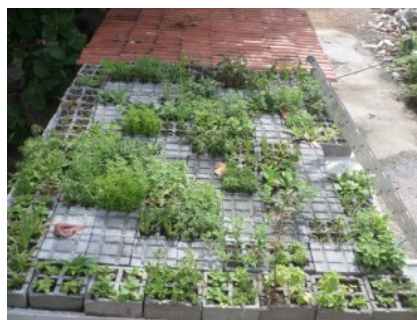

$06 / 11 / 2014$

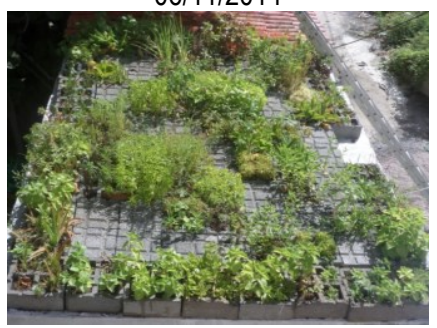

$06 / 01 / 2015$

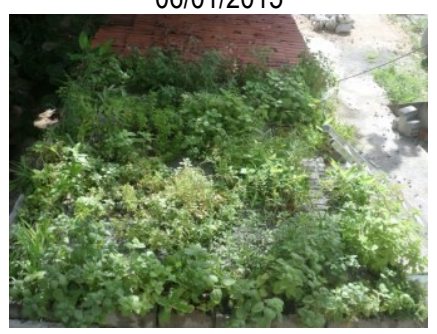

$06 / 03 / 2015$
Fonte: Os autores.

O primeiro destaque dado é o desenvolvimento da vegetação, observável na sequência das imagens (Figura 7). Para esse período, foram registradas várias estratégias sobre o telhado verde: manutenção sistemática, realizada através de fornecimento de água aos vegetais, pelo menos, 3 (três) vezes por semana; e retirada de vegetais invasores, uma vez ao mês. Dentre as constatações, destaca-se o desenvolvimento espontâneo de espécies vegetais, junto às plantas cultivadas. Outras ocorrências foram também observadas, tais como: folhas amareladas, sistema radicular atravessando a base do bloco, casulos de formigas e, até mesmo, o surgimento de cupim. Esta última ocorrência já havia sido constatada na edificação onde a cobertura verde foi instalada. Compreende-se, então, que o cupim ampliou sua área, colonizando também o telhado verde. A Figura 8 apresenta algumas imagens representativas dos fenômenos observados.

Figura 8 - Algumas imagens representativas dos animais atraídos para o telhado verde em teste na $2^{\mathrm{a}}$ etapa de acompanhamento - período seco

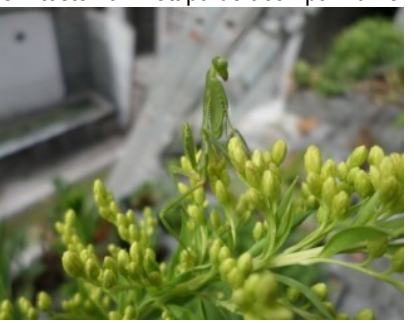

Louva-a-deus (Insecta)

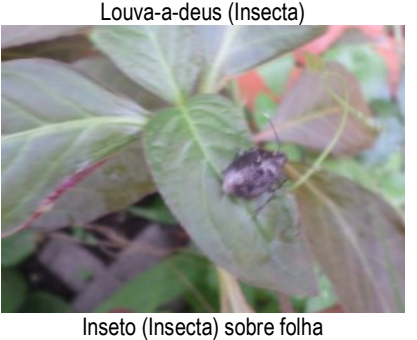

Fonte: Os autores

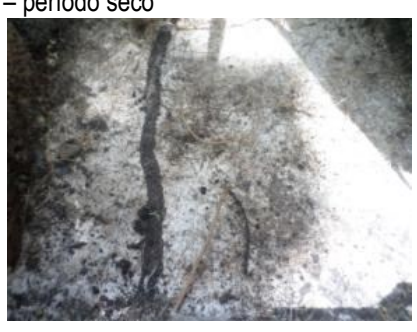

Cupim (Insecta) sob os blocos

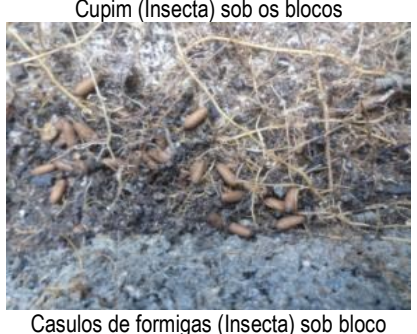

Tanto na primeira etapa de acompanhamento quanto na segunda foram encontradas algumas variedades de animais, tais como: baratas, minhocas, formigas, embuás, entre outros. Outros animais que foram vistos a visitar o telhado em teste, como borboletas e abelhas, não foram captados para registro. A diversidade de animais observados confirma que o telhado verde executado com os blocos TEVA tem potencial para criar micro-habitat. Esse fato está de acordo com Williams et al. (2010), que credita aos telhados verdes a capacidade de auxiliar na manutenção da biodiversidade urbana.

Nesta etapa de monitoramento, foi identificado que das 32 espécies vegetais cultivadas nos blocos TEVA que foram instalados no telhado verde em teste, 20 (63\%), destacadas no Quadro 4, se adaptaram bem às condições locais.

Por outro lado, no telhado verde em teste nesse período de monitoramento, ocorreram, no mínimo, mais 14 espécies (sp.) invasoras que se desenvolveram paralelamente às cultivadas. Dunnet et. al. (2008), em seus estudos, também identificaram espécies colonizadoras, precisamente 35 espécies, nos telhados verdes analisados, o que está de acordo com Köhler (2006), quando afirma que os telhados verdes são dinâmicos e a vegetação é susceptível a alterações.

De certa forma, o desenvolvimento de espécies vegetais invasoras no telhado verde com blocos TEVA (que tem 
profundidade das células para acomodar o solo e vegetais igual a $10 \mathrm{~cm}$ ) em teste já era esperado, tendo em vista os resultados obtidos por Oberndorfer et. al. (2007), quando constatou que substratos com profundidade de $7 \mathrm{~cm}$ a 15 cm são mais hospitaleiros a ervas daninhas do que os substratos mais rasos. Isto é decorrente do simples fato de que maiores profundidades dispõem de maiores recursos para os vegetais. Esse fato pode ser visto como um fator positivo, significando que o próprio telhado verde em teste foi capaz de fazer uma auto reposição vegetal.

\begin{tabular}{|c|c|c|c|}
\hline Nome popular & Família & Nome científico & Característica \\
\hline Alho do mato & Iridaceae & Cipura paludosa Aubl. (1775) & Herbácea \\
\hline Babosa & Xanthorrhoeaceae & Aloe vera (L.) Burm. f. (1768) & Suculenta \\
\hline Boldo & Lamiaceae & Plectranthus barbatus Andrews (1810) & Herbácea/perene \\
\hline Bunina (da flor roxa) & Nyctaginaceae & Mirabilis jalapa L. (1753) & Herbácea \\
\hline Chachambá (anador) & Acanthaceae & Justicia pectoralis Jacq (1760) & Herbácea/altura $50 \mathrm{~cm}$ \\
\hline Capim santo & Poaceae & Cymbopogon citratus (DC.) Stapf & Herbácea \\
\hline Cana de macaco & Costaceae & Costus spicatus (Jacq.) Sw. (1788) & Herbácea de haste dura \\
\hline Camomila & Asteraceae & Matricaria recutita L. (1753) & Herbácea/perene \\
\hline Colônia & Zingiberaceae & Alpinia zerumbet. Pers. B.L. Burtt.\& R.M.Sm & Herbácea/perene \\
\hline Erva lanceta & Asteraceae & Solidago chilensis Meyen (1834) & Subarbusto/perene \\
\hline Erva cidreira & Lamiaceae & Melissa officinalis L. (1753) & Herbácea/perene \\
\hline Hortelã Homem & Lamiaceae & Plectranthus barbatus Andrews (1810) & Herbácea/perene \\
\hline Hortelã da folha graúda & Lamiaceae & Coleus amboinicus Lour (1790) & Herbácea/perene/suculenta \\
\hline Mangericão menino & Lamiaceae & Ocimum minimum L. (1753) & Herbácea \\
\hline Malmequer amarelo & Asteraceae & Aspilia montevidensis (Spreng.) Kuntze (1898) & Herbácea/perene \\
\hline Milona & Menispermaceae & Cissampelos sympodialis Eichler (1864) & Trepadeira \\
\hline Penicilina & Amaranthaceae & Alternanthera brasiliana (L.) Kuntze (1891) & Herbácea/perene/ereta \\
\hline Saião & Crassulaceae & Kalanchoe brasiliensis Cambess & Suculenta \\
\hline Saião do roxo & Crassulaceae & Kalanchoe crenata (Andrews) Haw (1812) & Suculenta \\
\hline Salsa & Apiaceae & Petroselinum sativum Hoffm. (1814) & Herbácea \\
\hline
\end{tabular}

Fonte: Os autores.

Durante o acompanhamento no período seco (pouca chuva na cidade), precisamente no quarto mês (janeiro/2015), verificou-se, em praticamente todos os blocos TEVA, um rebaixamento do nível do substrato em até 4 (quatro) centímetros, sendo adotada a reposição imediata. Esse fenômeno pode ser relacionado à compactação do material no interior das células e/ou ao carreamento de material pela ação do vento.

Diante dessas observações, questiona-se a indicação da Associação Internacional de Telhados Verdes (IGRA, 2017) de que os telhados verdes extensivos não precisam de manutenção, mais que uma vez ao ano, bem como não precisam de irrigação. De fato, essa indicação é para o caso de se usar plantas suculentas e, talvez, para um determinado regime climático. Contudo, a considerar o cultivo de plantas medicinais de porte herbáceo, com substrato com 10 (dez) $\mathrm{cm}$ de profundidade, como foi feito no presente estudo, na condição de clima tropical quente e úmido, é indicada a realização de manutenções periódicas em menor intervalo de tempo. Os resultados do presente estudo demonstraram que, para o micro clima local no período seco de monitoramento, há necessidade de reposição do substrato nos blocos TEVA em apenas 4 meses e o fornecimento de água de 3 a 4 vezes por semana. Para o período chuvoso, pode-se até deixar sem fazer irrigação sistemática. Em todo caso, os resultados demonstraram que a irrigação e a manutenção do telhado verde constituem fatores fundamentais, indispensáveis, para manter a vitalidade das plantas.Além disso, como discutido anteriormente, observou-se o desenvolvimento espontâneo de outros vegetais, de modo que, se a intenção é manter apenas as espécies selecionadas, é imprescindível uma manutenção no mínimo mensal, para a retirada das espécies invasoras. Por outro lado, se o objetivo do telhado verde for se auto reconfigurar com as espécies invasoras, pode-se até dispensar esse tipo de manutenção. Isto, de certo modo, é considerado até mais sustentável. Como apontado na literatura e reportado aqui, há discussões com relação a um tipo especial de telhado verde, o telhado marrom, cuja cobertura recebe todas as camadas do telhado verde comum, exceto a vegetação, uma vez que se objetiva sua colonização pelas espécies nativas do entorno, onde está inserida a cobertura. Inclusive, ao longo do tempo, com a composição vegetal variando, conforme o que se desenvolve.

Por fim, há de se ressaltar que os blocos TEVA propostos não se apresentaram como um problema no desenvolvimento dos vegetais. Destacam-se as condições de espaço suficiente (profundidade) para receber $o$ substrato/vegetais e a permeabilidade da base para drenagem do eventual excesso de água no substrato. Os 
resultados demonstraram que o material utilizado na fabricação dos blocos TEVA, cimento Portland, areia natural e agregados leves de EVA (resíduos da indústria de calçados) não agrediram o desenvolvimento dos vegetais.

\section{Conclusão}

A partir do monitoramento, ao longo de 9 (nove) meses, do telhado verde modular extensivo com uso dos blocos TEVA, instalado em escala real sobre uma coberta de uma edificação existente no laboratório (LABEME-CTUFPB), na condição de clima tropical quente e úmido, foi possível concluir o seguinte:

- A maioria $(63 \%)$ dos tipos de vegetais (plantas medicinais: hortelã da folha grossa, saião do verde e do roxo, boldo, cana de macaco, babosa, milona etc.), cultivados nos blocos TEVA, apresentou bom desenvolvimento, indicando que os mesmos se adequaram bem ao material (compósito cimentício leve com resíduos de EVA) e aos espaços das células ocupadas;

- As plantas medicinais de porte herbáceo cultivadas nas células dos blocos TEVA demandaram, pelo menos, uma manutenção mensal, para a retirada das espécies invasoras, o que deve ser feito sempre que a intenção seja manter apenas as espécies selecionadas inicialmente;

- O fornecimento de água, no período seco, ou seja, com baixa precipitação pluviométrica (nesse estudo com média mensal de $33,8 \mathrm{~mm}$ ), precisou ser, no mínimo, 3 a 4 vezes por semana, para manter a vitalidade das plantas. No período chuvoso, com maior precipitação pluviométrica (com média mensal de 171,9 mm), a irrigação foi dispensável;

- A manta com barreira anti raiz sob os blocos TEVA não pode ser dispensada, uma vez que se constatou que as raízes atravessam a base do bloco TEVA e podem se fixar na laje de suporte;

- O micro-habitat foi favorecido, na medida em que vários tipos de animais (minhocas, baratas, tatuzinho de jardim, embuá, caramujo etc.) foram atraídos para o local onde os blocos TEVA vegetados estavam dispostos sobre a laje, confirmando a capacidade do telhado verde em auxiliar na manutenção da biodiversidade urbana, conforme afirma Williams et. al. (2010).

\section{Agradecimentos}

A CAPES, pelo financiamento parcial da presente pesquisa, ao Laboratório de Ensaios de Materiais e Estruturas (LABEME), do Centro de Tecnologia da Universidade Federal da Paraíba (UFPB) e ao Centro de Biotecnologia (CBIOTEC) da UFPB, que deram suporte para a realização dessa pesquisa.

\section{Referências}

BERARDI, U; GHAFFARIANHOSEINI, A; GHAFFARIANHOSEINI, A. State-of-the-art analysis of the environmental benefits of green roofs. Applied Energy, v. 115, n.4, p. 411-428, abr. 2014. ISSN: 0306-2619.

https://doi.org/10.1016/j.apenergy.2013.10.047

BRAAKER, S.; GHAZOUL, J.; OBRIST, M. K.; MORETTI, M. Habitat connectivity shapes urban arthropod communities: the key role of green roofs. Ecology, v. 95, n.4 p. 1010-1021, abr. 2014. ISSN: 1939-9170. https://doi.org/10.1890/13-0705.1

BRENNEISEN, S. Space for urban wild life: designing green roofs as habitats in Switzerland. Urban Habitats, v. 4, n. 1, p. $27-$ 36, dez. 2006. ISSN: 1541-7115. Disponível em: http://www.urbanhabitats.org/v04n01/wildlife_pdf.pdf. Acesso em: 22 Maio 2017

COFFMAN, R.R; WAITE, T. Vegetated roofs as reconciled habitats: Rapid assays beyond mere species counts. Urban Habitats. v. 6, n. 1, jul. 2011. ISSN: 1541-7115. Disponível em: http://www.urbanhabitats.org/v06n01/vegetatedroofs_full.html. Acesso em: 22 Maio 2017

DUNNETT, N.; NAGASE, A.; HALLAM, A. The dynamics of planted and colonising species on a green roof over six growing seasons 2001-2006: Influence of substrate depth. Urban Ecosystems, v. 11, n. 4, p. 373-384, dez. 2008. ISSN: 1573-1642. https://doi.org/10.1007/s11252-007-0042-7

IGRA. Green roof types. Disponível em: http://www.igra-world.com/. Acesso em: 22 Maio 2017.

INMET. Instituto Nacional de Meteorologia. BDMEP. Banco de Dados Meteorológicos para Ensino e Pesquisa. Disponível em: http://www.inmet.gov.br/projetos/rede/pesquisa/. Acesso em 18 agosto 2016. 
ISHIMATSU, K.; ITO, K. Brown/biodiverse roofs: A conservation action for threatened brownfields to support urban biodiversity. Landscape and Ecological Engineering, v. 9, nº 2, p. 299-304, jul. 2013. ISSN: 1860-188X. https://doi.org/10.1007/s11355-0110186-8

KÖHLER, M. Long-Term Vegetation Research on Two Extensive Green Roofs in Berlin. Urban Habitats. v. 4, $\mathrm{n}^{\circ} 1$, p. 3-26, 2006. ISSN: 1541-7115. Disponível em: http://www.urbanhabitats.org/v04n01/berlin_full.html. Acesso em: 22 Maio 2017.

KÖHLER, M.; POLL, P. H. Long-term performance of selected old Berlin green roofs in comparison to younger extensive green roofs in Berlin. Ecological Engineering, v. 36, n. 5, p. 722-729, mai.2010. ISSN: 0925-8574

https://doi.org/10.1016/j.ecoleng.2009.12.019

OBERNDORFER, E.; LUNDHOLM, J.; BASS, B.; COFFMAN, R. R.; DOSHI, H.; DUNNETT, N.; GAFFIN, S.; KÖHLER, M.; LIU, K.K.Y.; ROWE, B. Green roofs as urban ecosystems: ecological structures, functions, and services. Bioscience, v. 57, n. 10, p. 823-833, nov. 2007. ISSN: 1525-3244. https://doi.org/10.1641/B571005

OLLY, L.M.; BATES, A.J.; SADLER, J.P.; MACKAY, R. An initial experimental assessment of the influence of substrate depth on floral assemblage for extensive green roofs. Urban Forestry and Urban Greening. v. 10, n. 4, p. 311-316, 2011. ISSN: 16188667. https://doi.org/10.1016/j.ufug.2011.07.005

TONIETTO, R.; FANT, J.; ASCHER, J.; ELLIS, K.; LARKIN, D. A comparison of bee communities of Chicago green roofs, parks and prairies. Landscape and Urban Planning, v. 103, n. 1, p. 102-108, out. 2011. ISSN: 0169-2046.

https://doi.org/10.1016/j.landurbplan.2011.07.004

TROPICOS. Missouri Botanical Garden. 2017. Disponível em:< http://www.tropicos.org>. Acesso em: 12 Set. 2017.

WILLIAMS, N.S.G.; RAYNER, J.P.; RAYNOR ,K.J. Green roofs for a wide brown land: opportunities and barriers for rooftop greening in Australia. Urban Forest Urban Green, v. 9, n. 3, p. 245-251, 2010. ISSN: 1618-8667

https://doi.org/10.1016/j.ufug.2010.01.005

\footnotetext{
${ }^{1}$ Tatyane Nadja Martins de Mendonça

Bióloga pela Universidade Federal da Paraíba. Mestre em Engenharia Civil e Ambiental/UFPB. Rua Radialista Antônio Assunção de Jesus, 89, João Pessoa, Paraíba, Brasil, 58052-230.
}

\section{${ }^{2}$ Aluísio Braz de Melo}

Arquiteto pela Universidade Federal da Paraíba. Doutor em Ciência e Engenharia de Materiais/EESC-USP. Avenida Guarabira, 1125, João Pessoa, PB, Brasil, 58038-142. 